\section{ENTRE EL BANCO, LA CASA Y LA PAH: UNA VISIÓN DE LA COTIDIANEIDAD EN CRISIS A TRAVÉS DE LA LUCHA DE LAS PERSONAS AFECTADAS EN BONAVISTA (BARCELONA)}

\author{
Georgios Azis \\ Universidad de Uppsala \\ http://orcid.org/0000-0001-6363-4244 \\ yorgosaz@gmail.com
}

\section{BETWEEN THE BANK, THE HOUSE AND THE PAH: A VIEW OF QUOTIDIAN LIFE IN CRISIS THROUGH THE STRUGGLE OF THOSE AFFECTED IN BONAVISTA (BARCELONA)}

Cómo citar este artículo/Citation: Azis, G. (2019). Entre el banco, la casa y la PAH: una visión de la cotidianeidad en crisis a través de la lucha de las personas afectadas en Bonavista (Barcelona). Arbor, 195 (793): a515. https://doi.org/10.3989/ arbor.2019.793n3003

Recibido: 12 febrero 2016. Aceptado: 31 marzo 2016.

RESUMEN: La gran recesión del 2008 fue un evento singular en la historia reciente del Estado español. El "pinchazo" de la burbuja inmobiliaria y la destrucción masiva de empleo que trajo consigo pusieron de manifiesto la crisis profunda del capitalismo hispano. En Bonavista el paro y la consiguiente incapacidad de la gente trabajadora para pagar su deuda hipotecaria dieron lugar al ejercicio de una presión asfixiante por parte del sector financiero y a una reconfiguración de la cotidianeidad de las personas afectadas, que tuvieron que subordinar las relaciones sociales y la dedicación que hace falta para mantenerlas y para aumentarlas a la lógica de la expropiación de riqueza. En este contexto, la Plataforma de Afectados por la Hipoteca (PAH) surge como un refugio donde las personas afectadas reclaman la primacía de sus proyectos de vida frente a la pretendida hegemonía de la banca.

PALABRAS CLAVE: Cotidianeidad; trabajo; producción social; subordinación; Plataforma de Afectados por la Hipoteca (PAH).
Copyright: (C) 2019 CSIC. Este es un artículo de acceso abierto distribuido bajo los términos de la licencia de uso y distribución Creative Commons Reconocimiento 4.0 Internacional (CC BY 4.0).

ABSTRACT: The Great Recession of 2008 was a singular event in the recent history of Spain. The burst of the real-estate bubble and the massive destruction of jobs it provoked revealed a deep crisis in Spanish capitalism. In Bonavista, unemployment and the resulting inability of working people to pay their mortgages exerted intense pressure on the financial sector to reshape the quotidian life of those affected, resulting in: the subordination of social relations, the labour required to maintain these and their reproduction to the logic of wealth expropriation. In this context, the Plataforma de Afectados por la Hipoteca (Platform for People Affected by Mortgages, PAH) arises as a refuge, where afflicted persons reclaim the primacy of their life projects against the attempted hegemony of the banks.

KEYWORDS: Quotidian life; labour; social production; subordination; Plataforma de Afectados por la Hipoteca (PAH). 


\section{INTRODUCCIÓN}

\section{Abordando la cotidianeidad}

La erupción de la crisis financiera en 2008 fue un evento singular en la historia de la economía global. Grandes corporaciones financieras cuyos negocios se extendían a escala internacional quebraron; el crédito en el mercado interbancario de préstamos se congeló; el paro se disparó en los Estados Unidos y en los países más afectados de Europa hasta alcanzar los dos dígitos; y millones de personas perdieron sus casas por su incapacidad de continuar pagando sus hipotecas (Harvey, 2010, pp. 17-18). En España, en particular, la caída del mercado inmobiliario y la destrucción masiva de empleo que ella conllevó puso de manifiesto la crisis del "capitalismo hispano" o el modelo basado en la construcción y el turismo como los principales promotores de la economía financiados -en gran parte- por un extenso endeudamiento privado (López y Rodríguez, 2010; Palomera 2013; Palomera, 2014). La exclusión residencial se acentuó, dejando sin hogar a jóvenes, familias desahuciadas y de inmigrantes, y ancianos (Sánchez Morales, 2012, pp. 314-316). La ciudadanía salió en masa a la calle para protestar contra la socialización de las pérdidas a través de la imposición de políticas de austeridad por los gobiernos del PSOE (2008-2011) y del PP (2011-2015).

En este contexto de agitación política, Keith Hart y Horacio Ortiz hicieron una llamada a los antropólogos, argumentando sobre la necesidad de concretar las consecuencias de carácter distributivo provocadas por la crisis financiera (Hart y Ortiz, 2008, p. 2). Una manera clara de llevar a cabo esta meta antropológica es a través del análisis de sus efectos en la vida cotidiana de la población y utilizando la etnografía como el principal modo de investigación. De hecho, la observación participante permite abordar cómo la disponibilidad de crédito puede potenciar o perturbar la realización de los proyectos de vida personales y familiares centrándose en la perspectiva de la gente afectada, cuya presencia en la bibliografía sobre la financiarización de la economía es más que limitada (Palomera, 2015, 24 agosto). Sin embargo, es preciso el desarrollo de un marco teórico que permita entender la crisis como un evento histórico en el que la industria financiera no aparezca como una institución estática y distanciada, sino como un actor social cuyas acciones implican unos cambios concretos para la cotidianeidad de la población trabajadora. Por lo tanto, opté por abordar la cotidianeidad de las personas afectadas basándome en los términos de trabajo y de la producción social.

En los últimos 40 años, la organización de la producción de mercancías en Europa y los Estados Unidos ha pasado por unos cambios estructurales significativos. El aumento del peso de los servicios en la economía, la deslocalización de la industria pesada hacia países como China y la desvinculación entre la productividad y el salario real significaron el deterioro de las condiciones de vida para la clase trabajadora. Más importante aún, el desmantelamiento del estado de bienestar creó un vacío que la industria financiera aprovechó para posicionarse, de modo que la satisfacción de las necesidades básicas de la población pasó a depender cada vez más del acceso al crédito (Lapavitsas, 2012, p. 34). Todos estos cambios históricos hacen que los términos de la producción y el trabajo sean imprescindibles para la comprensión de la cotidianeidad. No obstante, siguen siendo bastante limitados en su contenido, refiriéndose casi exclusivamente a la dimensión material del proceso productivo y, por lo tanto, tienen un escaso valor descriptivo como para que sean aplicables en el análisis antropológico de la rutina diaria.

El trabajo de Donald L. Donham sobre el materialismo histórico puede servir como punto de inicio para la antedicha necesidad de reconsideración terminológica. A partir de su lectura crítica de la idea de la naturaleza humana desarrollada por Karl Marx, Donham argumentó que el proceso de trabajo no debe ser visto solamente como la producción de mercancías, sino también como un proceso de "autoformación" (self-creation) humana (Donham, 2012, p. 398). Los seres humanos se crean a ellos mismos por medio de una "acción simbólicamente formada en el mundo"; la creatividad, la autoexpresión y la estética impregnan la actividad humana y son transformadas por ella (Donham, 2012, pp. 398-399). De una manera similar, David Graeber desarrolló un enfoque más amplio de la producción que, aparte de la creación de objetos materiales, incluye la formación de los productores y sus relaciones sociales (Graeber, 2001, pp. 58-59). Las sociedades, por consiguiente, se pueden distinguir según los fines y principios que rigen su sistema productivo: las sociedades no capitalistas o "economías humanas" se caracterizan por la subordinación de su producción material a la creación de las personas, mientras que las "economías comerciales" o economías de mercado priorizan la producción y la distribución de bienes materiales (Graeber, 2012, p. 412). En ambos tipos de configuraciones socioeconómicas el proceso de la formación humana contiene todo lo que tiene que ver con el criar y cuidar a las personas: 
"[...] las familias se crean, crecen y se rompen; la gente nace, madura, se reproduce, se hace mayor y se muere. [La gente] se socializa constantemente, se entrena, se educa, es guiada (mentored) hacia nuevos roles -un proceso que no se limita a la infancia, sino que dura hasta la muerte-; es cuidada constantemente. En esto consiste principalmente la vida humana; de lo que mucha gente dedica la mayor parte de su tiempo a preocuparse; en lo que nuestras pasiones, obsesiones, amores e intrigas tienden a centrarse; por la descripción de lo cual grandes novelistas y dramaturgos se hacen famosos; con lo que la poesía y el mito luchan por familiarizarse [...]" (Graeber, 2006, p. 73).

Recientemente, y en la misma línea que Donham y Graeber, Susana Narotzky y Niko Besnier han propuesto que la economía sea vista como el ámbito donde la gente se forma "en sus dimensiones físicas, sociales, espirituales, afectivas e intelectuales" (Narotzky y Besnier, 2014, p. 14). Así, desde estas perspectivas en su conjunto, la producción puede expandirse para acoger la dimensión simbólica hasta convertirse en el propio proceso de la vida (life process), dándonos la primera premisa en la que se basa la argumentación de este artículo: la cotidianeidad puede ser entendida como la diaria coordinación de los diferentes trabajos orientados hacia la producción de las personas.

\section{La subordinación de la cotidianeidad a la industria financiera}

La experiencia humana se forma por la reacción y por la respuesta social a la creciente presión ejercida por las fuerzas de (re)estructuración de la cotidianeidad; en nuestro caso, la presión monetaria y psicológica ejercida por la industria financiera y basada en el nexo gubernamental-financiero español. El hablar de la existencia de un nexo entre el gobierno y las finanzas significa abordar la regulación financiera como un resultado histórico de la "acomodación entre las élites del Estado y el sector bancario privado" (Pérez, 1997, p. 44). Además, si aplicamos la lógica promovida por David Graeber en su trabajo sobre la burocracia, según la cual la "alianza entre el gobierno y las finanzas" (Graeber, 2015, p. 21) se contrapone a la sociabilidad humana, podemos observar un hecho interesante: en las últimas tres décadas, la distribución desigual de la protección estatal suscribe la relación de subordinación entre la banca y la gente afectada. Por una parte, la liberalización del mercado hipotecario español y su apertura a los flujos del capital internacional, en combinación con la introducción de innovaciones financieras como la titulización, permitió la expansión de la actividad crediticia bancaria (López y Rodríguez, 2010, pp. 188-189). Por otra parte, ese mismo proceso agudizó la exposición social de la población a través de su endeudamiento masivo, transfiriendo los costes de una potencial quiebra a los deudores. Por ejemplo, hasta 2013, "las entidades financieras podían iniciar el vencimiento anticipado de la hipoteca y reclamar la totalidad de la deuda pendiente con tan sólo un mes de impago". El banco podía luego poner la propiedad a subasta y adjudicarla por un valor que no excedería el monto total de la deuda (véase Emergencia habitacional en el Estado español, pp. 57-58) ${ }^{1}$. De este modo, cuando estalló la burbuja inmobiliaria, muchas trabajadoras y sus familias quedaron desprotegidas y vieron su vida cotidiana subordinada a la demanda absoluta del pago de la deuda; una situación que se pone de relieve por la consiguiente ola de desahucios: desde 2007 más de medio millón de ejecuciones hipotecarias iban a presentarse en los juzgados de toda España2.

El nexo gubernamental-financiero es el locus donde se determinan las condiciones de pago de la deuda; o en términos más antropológicos, el horizonte de las posibilidades para acabar con la relación de subordinación a la que está sujeto el deudor. Esto se refleja en la serie de leyes adoptadas por los sucesivos gobiernos españoles durante los años de la crisis, con el declarado fin de proteger a los deudores hipotecarios. Según el artículo 3 del Real-Decreto Ley 6/2012, de medidas urgentes de protección de deudores hipotecarios sin recursos, por ejemplo, el deudor que quiere reestructurar su deuda tiene que demostrar con siete distintos tipos de documentación que se encuentra por debajo del "umbral de exclusión"; es decir, demostrar que no puede sustentarse por sí mismo. Del mismo modo, el Real-Decreto Ley 27/2012, de medidas urgentes para reforzar la protección a los deudores hipotecarios, establece en sus dos primeros artículos una moratoria de los desahucios para todas aquellas personas que pertenezcan a una de las siete categorías de "especial vulnerabilidad" y que cumplan cuatro criterios económicos según nueve tipos de certificados, declaraciones y contratos. Mientras, según el artículo 4 del más reciente Real-Decreto Ley $1 / 2015$, de mecanismo de segunda oportunidad, reducción de carga financiera y otras medidas de orden social, el deudor con problemas de pago podrá solicitar la "exoneración del pasivo insatisfecho" si es capaz de demostrar su "buena fe" acorde con cuatro requisitos diferentes. Así, todas estas leyes imponen una nueva capa burocrática que la gente afectada está obligada a penetrar para acceder a un régimen de protección estatal. Por el contrario, 
las autoridades estatales no imponen obligaciones sobre las instituciones financieras y las últimas pueden adherirse a las medidas de manera voluntaria. El Código de Buenas Prácticas, puesto en vigor con el RealDecreto Ley 6/2012 y modificado en el Real-Decreto Ley $1 / 2015$, se puede aplicar solo con la voluntad de la industria financiera y bajo la supervisión del Ministerio de Finanzas, el Banco de España, la Asociación Hipotecaria Española (AEB) y la Comisión Nacional del Mercado de Valores (CNMV), o sea, el nexo gubernamental-financiero español.

La dinámica transformativa de la cotidianeidad proviene y se nutre de las desigualdades sociales sancionadas por ley y mantenidas últimamente por la amenaza de la fuerza (Graeber, 2015, p. 58). En este sentido, la particularidad de la crisis hipotecaria es la creciente importancia, si no predominio, de la forma de subordinación basada en la deuda frente a formas más tradicionales como la explotación laboral por parte del capital productivo. Esta afirmación nos guía hacia la segunda premisa del artículo, es decir: que las complejas cadenas financieras que conectan a miles de familias con sus balances de activos, apoyadas por el aparato legal y represivo del Estado, permiten a los bancos mantener su preponderancia en temas financieros y expandirla a otros aspectos de la cotidianeidad de los deudores.

Así, y con el fin de comprender cómo la última gran crisis capitalista y la antedicha preponderancia de la industria financiera afectaron a la cotidianeidad de millones de personas en España, realicé mi trabajo de campo con la Plataforma de Afectados por la Hipoteca en el contexto de mis estudios de máster en el Departamento de Antropología Cultural y Etnología de la Universidad de Uppsala, Suecia. En concreto, la pregunta que voy a responder en las siguientes páginas es: ¿cómo la industria financiera reclamó su preponderancia en la cotidianeidad de las personas afectadas en el municipio periférico de Bonavista ${ }^{3}$ y cuál fue el papel de la Plataforma de Afectados por la Hipoteca en dicho proceso?

Mi investigación duró seis meses, de enero a abril y de julio a octubre de 2014, y tuvo lugar en la comarca del Barcelonès, tanto en la ciudad de Barcelona como en Bonavista. Las herramientas metodológicas elegidas fueron la observación participante de las actividades de la Plataforma de Afectados por la Hipoteca (p. ej. las asambleas de bienvenida y coordinación, las acciones contra la industria financiera etc.) y las entrevistas semi-estructuradas que realicé con miembros del movimiento en los centros urbanos mencionados anteriormente (los datos se recogen en la tabla 1 ).

\section{Localizando la cotidianeidad y su subordinación en el mapa: Bonavista}

Bonavista es el nombre ficticio de un municipio en el que a lo largo de su historia reciente se han observado muchas transformaciones debidas a su condición periférica respecto a Barcelona. En particular la creciente importancia de la capital catalana como centro industrial, tanto en la época de la preguerra como durante los años del franquismo, tuvo como consecuencia que cientos de miles de inmigrantes llegaran desde el interior de España en busca de mejores condiciones de trabajo y remuneración (Riquer, 2010, p. 638). Muchos de ellos no pudieron encontrar un alojamiento asequible en Barcelona y se trasladaron a los municipios como Bonavista que más tarde constituirían la periferia obrera de la Ciudad Condal.

La crisis económica de los 70 abrió el camino para un cambio estructural en la naturaleza del modelo socioeconómico que tuvo lugar durante las siguientes tres décadas: la industria tradicional fue desplazada por las industrias farmacéutica, alimentaria, química y de la construcción, cuya operación se basó en "pirámides de subcontratación", extendiéndose en la to-

Tabla 1. Datos de los informantes y relación con la hipoteca.

\begin{tabular}{|c|c|c|c|c|c|c|}
\hline Informantes & Seudónimo & Género & Edad & País de origen & Ocupación & $\begin{array}{c}\text { Relación con la } \\
\text { hipoteca }\end{array}$ \\
\hline 1 & Aina & $\mathrm{F}$ & $* *$ & España & Desempleada & Contratante \\
\hline 2 & Marcela & $\mathrm{F}$ & $* *$ & Ecuador & Desempleada & Contratante \\
\hline 3 & Selma & $\mathrm{F}$ & $* *$ & Marruecos & Servicio de limpieza & Contratante \\
\hline 4 & Carla & $\mathrm{F}$ & $* *$ & Ecuador & Servicio de limpieza & Contratante \\
\hline 5 & Julio & $\mathrm{M}$ & $* *$ & España & Desempleado & Contratante \\
\hline 6 & Carlos & $\mathrm{M}$ & $* *$ & Bolivia & Desempleado & Contratante \\
\hline
\end{tabular}

a. La edad de las informantes es información confidencial que el autor de este artículo no tiene derecho a divulgar. b. Ocupación cuando se hizo la entrevista.

Fuente: Elaboración propia 
talidad de la Área Metropolitana de Barcelona y sus territorios adyacentes (Maldo, 2004, pp. 14-15). El nuevo régimen laboral se caracterizó por una precariedad permanente, cuyo impacto en la cotidianeidad de la gente trabajadora se agravó después del desplome de la burbuja inmobiliaria. Según la gran mayoría de mis interlocutores en Bonavista, no había trabajo o estaban trabajando con contratos temporales y, si encontraban algo nuevo, nadie pensaba que iba a durar más de unos meses.

La sensación de inestabilidad e incertidumbre y la expectativa de una rotación continua entre trabajos parece ser la regla en una ciudad donde el movimiento incesante de la gente en la calle, intentando materializar sus proyectos de vida personales o familiares, choca con la creciente necesidad de las grandes corporaciones de generar ganancias imponiendo un régimen de flexibilidad laboral.

\section{LA DEUDA: DESDE LA FACILITACIÓN A LA (RE)ESTRUC- TURACIÓN DE LA COTIDIANEIDAD DE LAS PERSONAS AFECTADAS}

Aina nació y creció en Cataluña. A principios de los 2000 trabajaba en una tienda de comida rápida y su novio como obrero en la construcción. Sus salarios les permitían cubrir sus gastos mensuales. Como explica en su entrevista:

\footnotetext{
“No vivíamos aquello... muy, muy, muy bien pero podíamos pagar las cosas y todo. Íbamos un poco desahogados por decirlo así".
}

Sin embargo, la enorme brecha entre "poder pagar" y comprar un piso solo podía cubrirse con la contratación de una hipoteca. El banco les ofreció el crédito para la compra del piso que hasta entonces estaban alquilando. Luego decidieron casarse y tuvieron que solicitar un préstamo personal para realizar todo aquello que es socialmente necesario para la ocasión. Además, y como si las anteriores deudas no fuesen bastantes, tuvieron que cambiar su coche averiado. De manera que al final los gastos combinados de los préstamos hipotecario y personal llegaron a un nivel que sería imposible seguir pagando sin poner en riesgo la viabilidad de su proyecto de vida común, más aún si se toma en cuenta que Aina estaba embarazada de su primer hijo. Así, Aina y su marido tuvieron que endeudarse porque las condiciones estructurales existentes no les concedían los recursos materiales e inmateriales necesarios para la producción social -la de ellos mismos, la de su hijo y de la gente en su entorno-.
Este punto pone de manifiesto la diferencia fundamental entre mis interlocutores y otros deudores más pudientes. Los primeros utilizaron el dinero prestado con el fin de adquirir un lugar donde habitar y participar en el trabajo de formación mutua, mientras que los últimos suelen tratar la propiedad como un activo financiero para la acumulación de riqueza mediante la especulación de precios. Claro está que los ricos deudores pueden tener familias cuyo bienestar puede ser tan importante para ellos como el progreso de sus negocios, mientras que las personas pertenecientes a la clase trabajadora pueden embarcarse en la compraventa de viviendas para mejorar su posición socioeconómica y estatus -como es el caso del "piso-puente" o el uso de la vivienda como activo financiero en Ciutat Meridiana, Barcelona (Palomera, 2011, p. 334). No obstante, cuando se trata del mercado hipotecario es posible distinguir entre la compra de una vivienda para la producción de seres humanos y la compra para la generación y acumulación de ganancias, ya que, cuantas más propiedades se poseen, más superfluas tienden a ser en el proceso de formación de la familia. No es casualidad que en España los únicos que verdaderamente pudieron beneficiarse de la inflación de los precios inmobiliarios durante la burbuja fueron los que ya tenían una fortuna acumulada (López y Rodríguez, 2010, pp. 417-418).

El desplome de la burbuja inmobiliaria y el fin del crecimiento vertiginoso de la economía española impactó desmesuradamente en la cotidianeidad de las personas afectadas por la exposición de sus vidas a la fuerza homogeneizadora de la extracción del beneficio financiero. En particular, y en contraste con el beneficio generado en la esfera de la producción, el beneficio financiero tiene sus orígenes en la esfera de la circulación y se refiere a los flujos de capitales disponibles para préstamos (loanable money capital) (Lapavitsas, 2013, pp. 138-168) ${ }^{4}$. En el sentido más amplio de la producción social, esto significa que las actividades especulativas de la haute finance no figuran como factores esenciales para la formación de personas. La deuda, al equiparar la vida humana a una simple cuantía de dinero (Graeber, 2011, pp. 13-14), colapsa la antedicha distinción permitiendo a las instituciones financieras invadir todos los ámbitos de la actividad humana y forzar la sustitución de los proyectos de vida personales y familiares por la transferencia expropiatoria de valor monetario a las cajas. Esto se ve, sobre todo, cuando el pago de las cuotas llega a competir con la necesidad de adquirir los medios de subsistencia. Como nos cuenta Aina: 
"[...] la lucha no es de meses. Son años. Años intentando porque cada vez se encarecía más la cosa, cobrabas lo mismo, y piensas «es que va a llegar un punto que no vamos a poder pagar», como se van subiendo las cosas y con el crío y todo es que no puedes pagar. Entonces vas pensando: «como no puedo pagar el piso, ¿qué hago?». Ya empiezas con el rollo mental, ¿vale?: «¿̀ qué hago?», «¿̀ qué hago?»... años de lucha constante contigo mismo, con tus creencias, con lo que te han inculcado desde pequeño... cada vez que tu hijo te pide no sé que [...] porque a lo mejor necesita [...] un niño tiene que comer fruta y comer verdura y tú no lo estás pudiendo ya comprar. Ya ni para él, ¿ivale?, [a mí me] da igual lo de comer o no comer [...] y piensas «¿qué hago? porque tengo que pagar la hipoteca»..." (Aina).

Marcela, de origen ecuatoriano, llegó a España en el 2000. Una de sus hijas padecía problemas respiratorios y, por recomendación médica, decidió buscar un tratamiento en Barcelona, seguida por el resto de su familia. La familia habitó la "ilegalidad" o "la estructura de desprotección jurídica y simbólica" (Palomera, 2013 , p. 308) hasta que fueron "legalizados" en una de las grandes operaciones de regularización realizadas por el Estado español. En aquel tiempo Marcela trabajaba en servicios de limpieza y hostelería, y su marido como obrero especializado en la construcción. Como en numerosos otros casos, tuvieron que endeudarse para acceder a una vivienda barata y en mejores condiciones de habitabilidad que la vivienda de alquiler. Sin embargo, la crisis financiera y las crecientes dificultades para pagar las cuotas mensuales transformaron su cotidianeidad en un círculo vicioso:

"[...] yo trabajaba todo el día, mi marido trabajaba día y noche y fines de semana. Y nuestras hijas solamente las pasábamos, era... en casa de uno, en casa de otro, las tenían cuidando, pagando porque... para coger y para... para salir adelante... a veces no nos alcanzaba, hacíamos otros préstamos para seguir pagando los préstamos que teníamos... decíamos «no, no, la hipoteca, la hipoteca, la hipoteca»" (Marcela).

La presión para que la sociabilidad humana funcionara como fuente de capital económico acumulado en forma de beneficio financiero se hizo más directa por el cambio radical del comportamiento de los empleados bancarios. Al principio, la disponibilidad de crédito barato y la necesidad de adquirir nuevos clientes hicieron que trataran a las personas afectadas de una manera amigable. Como nos cuenta Selma, una persona afectada que vino a Bonavista desde Marruecos:
"El trato del banco era bien, de maravilla. Hasta si yo quiero dinero más para reformar, para cualquier cosa, pues me pueden dar dinero más; digo: «anda ya, pues si el banco [me] está dando dinero eso es un lujo», es un lujo para mí en aquel momento. El banco te trata bien y... y no pasa nada y todo va bien y ya está" (Selma).

Sin embargo, el colapso de los precios inmobiliarios y la recesión económica forzaron la modificación de la estrategia de los bancos frente a la perspectiva de impago y el consiguiente daño en el balance de activos (Lapavitsas, 2007, p. 426). Las demandas para el cumplimiento de las obligaciones sustituyeron el tratamiento amigable a las personas afectadas y se hizo uso de la agresividad verbal. Este cambio fue acompañado de una intensificación general del acoso bancario: llamadas telefónicas al trabajo o a casa demandando el pago inmediato de la deuda, sea por la institución financiera que ofreció el crédito o por una agencia de recuperación de impagos a la cual el cobro de la deuda fue externalizado; avisos por correo y en términos como estos:

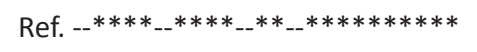

Préstamo con garantía hipotecaria a su nombre.

Por impago, declaramos vencida la operación, iniciándose procedimiento de ejecución-dineraria-hipotecaria.

A efectos legales, declaramos:

Saldo deudor a **/**/2011: ***.***,** euros, por

si desea hacerlo efectivo antes de la demanda.

$<$ Nombre del banco $>$

Ir al banco a negociar una solución con el argumento de sus nuevas circunstancias socioeconómicas llegó a ser una tarea emocionalmente agotadora para muchas personas afectadas. Cuando Carla, una compatriota de Marcela, compró su piso, la fase de extrema precariedad y explotación que vivió como una inmigrante recién llegada a España parecía haber terminado. Después de trabajar por un tiempo como trabajadora doméstica, consiguió sus papeles y trajo a sus hijas a Barcelona. Mientras pagaba su hipoteca y el flujo monetario seguía ininterrumpido hacia su cuenta bancaria, no había problemas con la institución financiera. Sin embargo, el descenso de sus ingresos y el retraso en los pagos llevaron a que el director encargado de su caso empezara a verla "como el patito feo". Como sigue contando:

"yo iba... mm... sí, iba bastante... pero temblando, con un miedo que no veas que... tenía hasta 
tanta vergüenza [por el] miedo de ir. Yo cuando ya me llamaban decía: «ahora ¿qué me van a decir?, ¿qué me van a obligar?» y esto. O sea, era... ¿sabes? Te pones nerviosa, te pones... tensa y sí que me iba... me iba cada... cuando me llamaban, pero no el día que ellos me llamaban sino me iba a los dos días, pero ya te digo: con un miedo terrible, terrible." (Carla).

La experiencia de Selma no fue diferente. Ella llegó a Cataluña en los años 90 aunque al principio no quería quedarse en España. Su gran ilusión era obtener los papeles del gobierno español para poder viajar hasta Francia y empezar una nueva vida allí. Después de trabajar unos años en talleres de confección de la "economía informal" obtuvo sus papeles pero decidió quedarse; algo que, en combinación con el fracaso de su matrimonio concertado, la convenció sobre las ventajas de adquirir una vivienda mediante una hipoteca. Posteriormente el aumento de las cuotas mensuales y la evolución negativa de sus finanzas fueron el principio de una tensa relación entre ella y el banco, relación que terminó con la desposesión de su dignidad como persona:

\footnotetext{
"la última vez cuando ya fui, pues... casi me hablaron mal... mal. Y digo: «pues, aquí ya no... nunca voy a volver, pase lo que pase» porque ya te sientes allí como si fuera... digo: "iyo no estoy pidiendo nada, yo estoy pidiendo un arreglo que pueda pagar, lo que puedo pagar, yo estoy trabajando!» (Selma).
}

Frente a un montón de recibos de pago y otros documentos relevantes acumulados a lo largo de sus años como persona endeudada, Selma ironiza sobre su situación: "este es mi legado, iestoy casada con una hipoteca!". Esta frase demuestra de una manera muy gráfica la subordinación de los proyectos de vida personales y, por consiguiente, de la cotidianeidad al imperativo de la acumulación financiera basada en la expropiación de valor monetario. La hipoteca llega a dominar su vida hasta el punto de que parece tomar el lugar de un participante activo en sus relaciones sociales más íntimas.

Además no se debe olvidar que la deuda funciona como vehículo de (re)estructuración de la cotidianeidad en el contexto de un mercado laboral azotado por la depresión económica. En particular, hay una conexión causal entre las fluctuaciones del (des) empleo y la exclusión residencial (Cabrera y Rubio, 2008, pp. 53-57; Sánchez Morales, 2012, pp. 317318), algo que el desenvolvimiento de la crisis puso de manifiesto: desde la primavera de 2007 hasta fi- nales de 2012, casi 3.000.000 de puestos de trabajo fueron destruidos y la falta de trabajo llegó a ser una de las principales razones por la que mucha gente quedó "sin hogar" (Davia Rodríguez y Álvarez Aledo, 2013, p. 112; Sánchez Morales, 2012). Así mismo en el período 2007-2009, el valor monetario de los créditos dudosos subió de los seis mil a más de 32 mil millones de euros (López y Rodríguez, 2010, p. 426). En términos antropológicos, el paro tuvo un efecto multiplicador en el proceso de reestructuración de la cotidianeidad a través de la deuda; ejerció una presión hacia abajo en el espacio socioeconómico, intensificando el desequilibrio de poder entre los deudores y el banco y aumentando la dependencia de los primeros de aquella gente que ocupa posiciones clave en la distribución de recursos.

Marcela fue varias veces a la asistenta social pero no recibió la ayuda que esperaba:

“... entonces oían, te miraban, ni te atendían ni se iban. Te dejaban aquí esperando: "ah, sí, sí, sí» te dejaban esperando desde las 9 de la mañana hasta las 12 del [medio]día. Tú veías que pasaba la gente, tú seguías ahí esperando y no te atendían. Ya entonces aparte de vivir la crisis de no pagar, tú vives la crisis emocional que te humilla, que tú tienes que agachar la cabeza, y tienes que verte hacer un frente para saber qué vas a hacer" (Marcela).

Esto es especialmente relevante si se toma en consideración que los informes de las asistentas sociales son imprescindibles para acceder a los recursos proporcionados por el Estado u otros proveedores como la Iglesia. Como nos cuenta Julio, el esposo de Aina:

“[...] en esto de la alimentación fuimos a la iglesia, y allí nos cogieron y nos estuvieron dando alimentos durante... seis meses. Después, claro, llegó un momento que al ser tanta gente, la Cruz Roja y el Caritas estaban saturados, saturados. Entonces el chico este [el asistente de los servicios sociales] nos hizo un informe, salimos ahí al párroco y con ese informe nos estuvieron dando alimentos durante un año... El informe era de asuntos sociales... nos hizo el informe para llevárselo a la iglesia, que ellos reciben los alimentos a través de Caritas" (Julio).

Así, el abastecimiento de la unidad doméstica, antes una relación entre los trabajadores y el supermercado o la tienda de comestibles del barrio, se hace más compleja desde el punto de vista de la coordinación de los trabajos por el aumento de intermediarios y la burocratización. 


\section{LA PAH COMO INTERPOSICIÓN ENTRE LAS PERSO- NAS AFECTADAS Y LA BANCA}

La Plataforma de Afectados por la Hipoteca es un movimiento social que apareció como una respuesta social al estallido de la crisis hipotecaria en el mapa político de Cataluña y de España en febrero de 2009. Fue fundada por activistas que hasta entonces estaban luchando por el derecho a una vivienda asequible bajo el nombre de $V$ de Vivienda (Colau y Alemany, 2013 , p. 87). Aunque pequeña al principio, su popularidad creció después de que el movimiento 15M o iDemocracia real ya! ocupara las calles y las plazas del país en la primavera de 2011. De hecho, muchos de los eslóganes de aquella época fueron adoptados por la Plataforma y utilizados en sus actividades de protesta. Un momento crítico para el movimiento llegó a principios de 2013 cuando, en colaboración con organizaciones de la sociedad civil y sindicatos, presentó la Iniciativa Legislativa Popular (ILP); es decir, una propuesta de ley cuyo objetivo era la introducción de una serie de medidas para la protección de la población endeudada contra las prácticas depredadoras de la industria financiera. Al final la ILP no fue aprobada por el Congreso de los Diputados. En julio de 2015, el Parlament de Cataluña aprobó por unanimidad otra ILP contra la emergencia habitacional, la cual contempla una serie de medidas legislativas contra los desahucios y mecanismos para la protección de familias en situación de extrema vulnerabilidad (http://ilphabitatge.cat/es/aprobada-por-unanimidad-la-ilp-contra-los-desahucios-y-la-pobreza-energetica/). De este modo, así como con acciones reivindicativas en la calle (ocupaciones de bancos y pisos vacíos etc.), la Plataforma ha logrado dar visibilidad a la problemática de los desahucios y establecerse como un interlocutor importante en el ámbito de la provisión de vivienda.

La PAH-Bonavista fue fundada en 2011 por unos activistas con una larga trayectoria en movimientos sociales. En el local donde realiza sus asambleas de bienvenida y asesoramiento colectivo la gente que no puede pagar sus préstamos hipotecarios sin perjudicar gravemente el sustento de sus familias pide ayuda a las personas afectadas con más experiencia para encontrar una solución a su difícil situación. Individuos de diferentes orígenes, profesiones y niveles educativos se encuentran y, a través de su experiencia del proceso hipotecario, intentan responder a las preguntas de los asistentes. Como en todas las Plataformas del país, dependiendo del caso particular, el apoyo ofrecido puede limitarse a la simple transferencia de información sobre los puntos relevantes del contrato hipotecario o puede ampliarse para incluir acompañamientos y acciones en las sucursales de las instituciones financieras. Las personas afectadas son la razón de ser de la Plataforma y su compromiso es crucial para que las actividades reivindicativas se lleven a cabo con éxito. Como se describe en un documento presentado en una de las reuniones de coordinación en agosto de 2014:

“... la Asamblea de la PAH-Bonavista [representa] el tiempo semanal más importante, para acoger a I@s nuev@s con toda su carga de angustia y preocupación, para asesorarnos para saber qué tenemos que hacer en cada momento del proceso judicial, acompañarnos cuando sea necesario, y para preparar las acciones de presión, aquí en Bonavista o en solidaridad con otras PAHs que lo solicitan, o incluso a nivel de toda Cataluña o de todo el Estado español, cuando se crea necesario".

El papel importante que la Plataforma ha adquirido en la cotidianeidad de las personas afectadas se me hizo patente en el ensayo de un sketch durante el Carnaval de 2014. Aquella tarde, la PAH-Bonavista iba a participar en las celebraciones de su ciudad y decidí visitar el local para ver los últimos preparativos. Cuando llegué, encontré una camioneta aparcada fuera con tres grandes pizarras blancas puestas alrededor del área de carga. En ellas, uno podía leer eslóganes como ¿Qué pasa?, ¿qué pasa?, que no tenemos casa y La PAH se va de Carnaval. Mientras intentaba imaginar lo que los activistas de la PAH iban a presentar ante miles de bonavistenses, entré en el local y encontré una multitud de gente disfrazada. En su mayoría llevaban las conocidas camisetas verdes de la PAH, con sombreros y capas verdes: eran los ImPAHrables, los superhéroes nacidos en los agitados años de la crisis financiera. La presencia dominante del color verde en el espacio del local se interrumpía por los uniformes negros de tres personas disfrazadas de agentes de la policía antidisturbios y por el uniforme caqui de otra persona disfrazada de guardia civil con su tricornio. Un poco más allá se encontraba en escena un ama de casa conversando con sus amigas sobre su plumero y su bata, y un banquero en toda su grandeza estereotipada: con traje, con su sombrero de copa alta dorado y cubierto de euros, fumando un puro y llevando una bolsa en la que se leía Hipoteca.

El último ensayo estaba a punto de empezar y todos los participantes fueron al fondo del local. Utilizado tanto para las asambleas de la PAH-Bonavista como para las reuniones, presentaciones y charlas de otras asociaciones y movimientos sociales, el espacio se convirtió en un gran escenario. En una de sus esqui- 
nas había una casa de cartón y enfrente tomaron sus posiciones el ama de casa, los policías, el guardia civil y el banquero. Los ImPAHrables ocuparon el resto del espacio. El guion era bastante simple: las fuerzas de seguridad intentarían desalojar al ama de casa y a su familia de su piso, todo bajo la mirada atenta del banquero mientras los ImPAHrables se moverían de aquí para allá cantando una adaptación de la famosa balada mexicana "la cucaracha" ${ }^{5}$. En algún momento, entre su canto y los gritos rítmicos de su nombre, los ImPAHrables liberarían a la familia de las manos de la policía. Hacia la mitad del ensayo, uno de los policías me miró, movió su porra en el aire y gritó "iMoroso, moroso! iDeben echar[te] de tu casa!"

Me quedé con esta frase al salir del Ateneu para caminar hasta el punto de inicio de la Rua de Carnaval. Según el artículo 2 de la ley 3/2004, por la que se establecen medidas de lucha contra la morosidad en las operaciones comerciales, y su posterior modificación contenida en la ley 15/2010, la morosidad es un concepto legal que se refiere al "incumplimiento de los plazos contractuales o legales de pago". La reacción espontánea del activista disfrazado como policía antidisturbios, en el contexto de la actuación de un sketch carnavalesco, impregnó el término de un sentido muy distinto a su dimensión legal: la morosidad llega a ser la situación inmoral según la cual el ser humano se reduce a una existencia social sin ninguna capacidad de defenderse. Se trata de la exposición de los procesos de vida de las personas afectadas a una variedad de agentes que tienen el derecho legal de ejercer sobre ellos violencia psicológica (banquero) y física (policía antidisturbios, guardia civil). El proceso hipotecario es un artificio social, del cual uno puede escaparse solo con la ayuda de la PAH.

La actuación carnavalesca de la PAH-Bonavista apunta a lo siguiente: con la crisis financiera, la deuda y el paro pusieron de manifiesto la falta de espacios que pudieran interponerse entre las personas afectadas y la banca o, dicho de otra manera, entre seres humanos con nada más que su capacidad de trabajar y una industria altamente burocratizada. Espacios donde la gente pueda defender y reivindicar la materialización de sus proyectos de vida particulares contra las demandas de las instituciones financieras. La Plataforma llegó a cubrir este vacío político. Sus fundadoras ofrecieron una visión alternativa al discurso dominante, según la cual ser moroso no era un problema personal y judicial, sino una emergencia colectiva y, por ende, claramente política: "no es una crisis sino una estafa". En sus procesos de ayuda y apoyo mutuos, las personas afectadas reclaman la primacía de la producción de personas en su cotidianeidad. El despliegue frecuente de los dilemas "pagar o comer" y "pan para hoy, hambre para mañana" realizado por los miembros veteranos de la PAH en las reuniones de bienvenida condensa en toda su dimensión material y simbólica la lucha contra la acumulación de riqueza como el régimen de valor dominante.

No obstante, este proceso político contiene al mismo tiempo el gran reto para toda aquella gente que acude con regularidad a las asambleas, las ocupaciones y las campañas públicas: cómo mantener la participación y el compromiso de las personas afectadas una vez resueltos sus casos. El esfuerzo que se requiere para llevar a cabo las diferentes actividades de la Plataforma no es exiguo: asesoramiento colectivo, acompañamientos, pasacalles de protesta, empapelar las sucursales por la noche, preparaciones de campañas, participación en el carnaval local, etc. Como nos cuenta Marcela:

"[...] cada día en la lucha... íbamos a cada rato a los servicios sociales, a los bancos, al ayuntamiento, a hacer recorridos por todos los bancos, a hacerles pegatinas, todo eso... a llamar a gente, a hacer que la gente se sensibilice, que digan que los casos existen..." (Marcela).

Cuanto mayor es la participación, más grande es el esfuerzo necesario para mantenerla. La disponibilidad de tiempo es un factor crucial para llevar a cabo con éxito las actividades diarias de la Plataforma. Además, en las conversaciones que tuve con Carlos, un obrero de la construcción de origen boliviano, se evidenció el esfuerzo mental y psíquico que implica conversar y debatir con otros compañeros:

"La Plataforma está ahí. Nosotros vamos como el muro de los lamentos. Vamos y nos lamentamos, nos quejamos, contribuimos, hacemos lo que podemos" (Carlos).

Dicho de otra manera, la formación y el mantenimiento de nuevas subjetividades políticas requiere un trabajo militante intensivo. Desde el punto de vista de la cotidianeidad, las exigencias de este tipo de trabajo en la rutina diaria de las personas afectadas pueden ser tales que su futuro se pone en peligro, al competir con otras aplicaciones de la creatividad e imaginación humanas como la de "ganarse la vida". Un día de septiembre estuve en una reunión previa a una asamblea de la PAH-Bonavista, sitio donde se prepara el contenido informativo, la estructura y los asuntos urgentes de la asamblea. Sus asistentes suelen ser 
de los más comprometidos, es decir, se encargan del abastecimiento de la PAH con material reivindicativo, siguen los casos y los acontecimientos diarios, y se dirigen a las personas afectadas y las asesoran durante la asamblea. Entre ellas estaba Carla, quien vino para enterarse de lo que estaba pasando, y sobre todo para informar de su situación actual. Por motivos de horario laboral, sus horas de trabajo se solapaban con la agenda semanal de la Plataforma y no podía seguir participando al cien por cien. "Siempre dedicaré el tiempo del que yo disponga", afirmó.

La constante de la precariedad, la brecha entre los recursos que cada afectado tiene o puede movilizar y los que se necesitan para la materialización de su proyecto de vida individual o compartido impregna la cotidianeidad y fuerza a elegir entre la necesidad de encontrar trabajo asalariado y la voluntad de seguir con el trabajo militante.

\section{CONCLUSIÓN}

Desde el colapso de la burbuja inmobiliaria y la subsiguiente recesión en países como los Estados Unidos o España, el término crisis se ha utilizado de manera desproporcionada por parte de medios de comunicación, políticos y tecnócratas. Pronto personas de toda índole empezaron a emplearla en su vida cotidiana, en su intento de racionalizar cómo, de un día para otro, millones de personas perdieron su trabajo. Este uso tan difuso, sin embargo, implica que su sentido está abierto a diferentes interpretaciones, según el prisma de la realidad social que cada uno vive. Como afirma Reinhart Koselleck, el concepto de crisis "continúa siendo tan multicapa y ambiguo como las emociones atadas a este" (Koselleck y Richter, 2006, p. 358). Mi trabajo de campo con la Plataforma de Afectados por la Hipoteca en Bonavista ha demostrado la veracidad de lo antedicho: para la gente endeudada, la crisis no representa meramente la caída de los salarios o la inmoralidad de los hombres de finanzas sino sobre todo la subordinación de su cotidianeidad a las exigencias financieras. Una forma de subordinación que está históricamente determinada y que es impuesta de manera particularmente cruda a la gran mayoría de la población trabajadora.
En particular, la institución financiera llega a reclamar su primacía en la cotidianeidad de los seres humanos, transformándola en fuente de acumulación de riqueza en forma de beneficio financiero. Por su naturaleza expropiatoria, este beneficio supone la invasión de todos los ámbitos que tienen que ver con la formación humana -con el piso o casa como el ejemplo principal- por parte de las demandas del banco. Además, la imposición de la subordinación viene acompañada de la burocratización de la provisión de recursos o de la exposición social a una variedad de agentes en posiciones estratégicas que llegan a determinar la viabilidad de los proyectos de vida de las personas afectadas. En este contexto, la cotidianeidad se transforma en un campo de batalla y la PAH-Bonavista surge como un refugio donde la gente afectada puede desafiar a la pretendida hegemonía de la banca, reclamando su protagonismo en su vida cotidiana.

El paso a una vida libre de cadenas financieras depende de la manera particular con la que se transforme la cotidianeidad. Se trata de una transformación abierta, expuesta a la contestación continua por los actores sociales, cuyo camino se hace cada vez más difícil de determinar por la fragmentación del escenario político. La derrota del bipartidismo en las elecciones generales del 20 de diciembre de 2015, el surgimiento de nuevas fuerzas políticas con representación institucional como Podemos y Ciudadanos, y la irrupción reciente del independentismo catalán suponen nuevos retos para el desarrollo de las diferentes subjetividades políticas, especialmente aquellas que fueron creadas y promovidas por la Plataforma en su lucha contra la subordinación de la vida humana a las finanzas.

\section{AGRADECIMIENTOS}

Este trabajo no habría sido posible sin la ayuda y cooperación de las activistas de la PAH-Bonavista, sin los comentarios y contribuciones críticos de Irene Sabaté Muriel y de Bálint Ábel Bereményi durante el proceso de la redacción del texto y sin el espacio público ofrecido por el simposio La crisis hipotecaria en el Estado español: impactos y respuestas sociales en el I Congreso AIBR, Antropólogos Iberoamericanos en Red (2015), convocado para una discusión profunda y crítica de la crisis hipotecaria española.

\section{NOTAS}

[1] En particular, y suponiendo que la subasta quedaba desierta, la propiedad podía adjudicarse por el $70 \%$ de su valor de tasación. Si este porcentaje cubría más del total de la deuda pen- diente, la institución financiera podía adjudicarla por un $10 \%$ menos.

[2] Según los datos estadísticos del Consejo General del Poder Judicial, la distribución de las ejecuciones hipotecarias iniciadas cada año entre 2007 y 2014 es la siguiente: 25.943 (2007), 58.686 (2008), 93.319 (2009), 93.636 (2010), 77.854 (2011), 91.622 (2012), 82.680 (2013) y 80.749 (2014) (véase Poder 
Judicial. España. Efecto de la crisis en los órganos judiciales).

[3] Seudónimo del municipio en la Área Metropolitana de Barcelona.

[4] Para Costas Lapavitsas el beneficio financiero es una forma distinta de beneficio

\section{BIBLIOGRAFÍA}

Cabrera, P. J. y Rubio, M. J. (2008). Las personas sin hogar, hoy. Revista del Ministerio de Trabajo e Inmigración, 75, pp. 51-74. [En línea]. Disponible en: http:// www.empleo.gob.es/es/publica/pub_ electronicas/destacadas/revista/numeros/75/est03.pdf

Colau A. y Alemany A. (2013). iSí se puede! Crónica de una pequeña gran victoria. Barcelona: Destino.

Davia Rodríguez, M. A. y Álvarez Aledo, C. (2013). El deterioro del mercado de trabajo tras cinco años de crisis: efectos laborales y sociales. Documentación social 166, pp. 109-126.

Donham, D. L. (2012). Epochal Structures I: Reconstructing Historical Materialism. En: Moore, H. L. y Sanders, T. (eds.) Anthropology in Theory. Issues in Epistemology. Chichester: Blackwell, pp. 397-406.

Graeber, D. (2001). Toward an anthropological theory of value: The false coin of our own dreams. Basingstoke: Palgrave Macmillan. https://doi. org/10.1057/9780312299064

Graeber, D. (2006). Turning Modes of Production Inside Out. Or, Why Capitalism is a Transformation of Slavery. Critique of Anthropology, 26 (1), pp. 61-85. https:// doi.org/10.1177/0308275X06061484

Graeber, D. (2011). Debt: The First 5,000 Years. New York: Melville House.

Graeber, D. (2012). On social currencies and human economies: some notes on the violence of equivalence. Social Anthropology, 20 (4), pp. 411-428. https://doi. org/10.1111/j.1469-8676.2012.00228.x

Graeber, D. (2015). The Utopia of Rules: On Technology, Stupidity, and the Secret Joys of Bureaucracy. New York: Melville House.

Hart, K. y Ortiz, H. (2008). Anthropology in the financial crisis. Anthropology Today, 24 (6), pp. 1-3. https://doi.org/10.1111/ j.1467-8322.2008.00624.x que no proviene de la explotación del trabajador sino de la expropiación, es decir la apropiación directa de valor de flujos monetarios ya existentes.

[5] La adaptación fue inspirada por las acciones de un representante del Partido Popular quien, en diciembre de 2013,

Harvey, D. (2010). The Right to the City: From Capital Surplus to Accumulation by Dispossession. En: Banerjee-Guha, S. (ed.) Accumulation by Dispossession: Transformative Cities in the New Global Order. Thousand Oaks, London, New Delhi: Sage Publications, pp. 17-32. http:// dx.doi.org/10.4135/9788132105923.n2

Koselleck, R. y Richter, M. W. (2006). Crisis. Journal of the History of Ideas, 67 (2), pp. 357-400. https://doi.org/10.1353/ jhi.2006.0013

Lapavitsas, C. (2007). Information and trust as social aspects of credit. Economy and Society, 36 (3), pp. 416-436. http://dx.doi. org/10.1080/03085140701428381

Lapavitsas, C. (2012). Financialised Capitalism: Crisis and Financial Expropriation. En: Lapavitsas, C. (ed.) Financialisation in Crisis. Leiden: Brill. https://doi. org/10.1163/9789004201088

Lapavitsas, C. (2013). Profiting Without Producing: How Finance Exploits Us All. London: Verso.

López, I. y Rodríguez, E. (2010). Fin de Ciclo. Financiarización, territorio y sociedad de propietarios en la onda larga del capitalismo hispano [1959-2010]. Madrid: Traficantes de Sueños. Disponible en: http://www.traficantes.net/sites/default/files/pdfs/Fin\%20de\%20ciclo-Traficantes\%20de\%20Sue\%C3\%B1os_0.pdf

Maldo, T. (2004). Barcelona en la glocalització. En: Unió Temporal d’Escribes. Barcelona, marca registrada. Un model per desarmar. Barcelona: Virus Editorial, pp. 13-26.

Narotzky, S. y Besnier, N. (2014). Crisis, Value, and Hope: Rethinking the Economy. Current Anthropology 55 (S9), pp. S4S16. https://doi.org/10.1086/676327

Palomera, J. (2011). Los efectos de la desresponsabilización del Estado en el espacio de la clase trabajadora, desde la óptica de la vivienda. En: Terradas Sabo- denunció a un miembro de la PAH por llamarle cucaracha. Aparte de defender a su comPAH, los activistas de la Plataforma tenían como objetivo el uso de la canción para la denuncia pública de la Ley de Seguridad Ciudadana, popularmente conocida como la ley mordaza. La ley entró en vigor el Julio de 2015.

rit, I. (coord.). Antropología jurídica de la responsabilidad. Santiago de Compostela: Andavira Editora, pp. 313-353.

Palomera, J. (2013). Transitar y habitar la «ilegalidad»: economías cotidianas migrantes. En: Narotzky, S. (ed.). Economías cotidianas, economías sociales, economías sostenibles. Barcelona: Icaria, pp. 307-336.

Palomera, J. (2014). How Did Finance Capital Infiltrate the World of the Urban Poor? Homeownership and Social Fragmentation in a Spanish Neighborhood. International Journal of Urban and Regional Research, 38 (1), pp. 218235. https://doi.org/10.1111/14682427.12055

Palomera, J. (2015, 24 agosto). Investing without wealth: The financialization of social reproduction crisis. [En línea]. Disponible en: http://allegralaboratory.net/ investing-without-wealth-the-financialization-of-social-reproduction-crisis/

Pérez, S. A. (1997). Banking on Privilege: The Politics of Spanish Financial Reform. Ithaca: Cornell University Press.

Riquer, B. de (2010). Historia de España (vol. 9. La dictadura de Franco). Madrid: Crítica / Marcial Pons.

Sánchez Morales, M. R. H. (2012). En los límites de la exclusión social: las personas sin hogar en España. OBETS. Revista de Ciencias Sociales, 7 (2), pp. 307-324. https://doi.org/10.14198/ OBETS2012.7.2.06

\section{Otros recursos}

Emergencia habitacional en el Estado español. La crisis de las ejecuciones hipotecarias y los desalojos desde una perspectiva de derechos humanos, diciembre de 2013. Observatorio DESC / Plataforma de Afectados por la Hipoteca. [En línea]. Disponible en https:// afectadosporlahipoteca.com/wp-content/uploads/2013/12/2013-Informe_ habtitatge-17Dic.pdf 
Poder Judicial. España. Efecto de la crisis en los órganos judiciales. Datos sobre el efecto de la crisis en los órganos judiciales desde 2007 hasta segundo trimestre de 2015. [En línea]. Disponible en http://www.poderjudicial.es/cgpj/es/Temas/EstadisticaJudicial/Estudios-e-Informes/Efecto-de-laCrisis-en-los-organos-judiciales/

\section{Textos legales}

Ley $3 / 2004$, de 29 de diciembre, por la que se establecen medidas de lucha contra la morosidad en las operaciones comerciales. Boletín Oficial del Estado, de 30 de diciembre de 2004, núm. 314, pp. 42334-42338. Disponible en: https:// www.boe.es/boe/dias/2004/12/30/ pdfs/A42334-42338.pdf
Ley 15/2010, de 5 de julio, de modificación de la Ley 3/2004, de 29 de diciembre, por la que se establecen medidas de lucha contra la morosidad en las operaciones comerciales. Boletín Oficial del Estado, de 6 de julio de 2010, núm. 163, pp. 59653-59660. Disponible en: https://www.boe.es/diario_boe/txt. php?id=BOE-A-2010-10708

Real Decreto-ley 6/2012, de 9 de marzo, de medidas urgentes de protección de deudores hipotecarios sin recursos. Boletín Oficial del Estado, de 10 de marzo de 2012, núm. 60, pp. 22492-22501. Disponible en: http://www.boe.es/diario_boe/txt.php?id=BOE-A-2012-3394
Real Decreto-ley 27/2012, de 15 de noviembre, de medidas urgentes para reforzar la protección a los deudores hipotecarios. Boletín Oficial del Estado, de 16 de noviembre de 2012, núm. 276, pp. 79877-79880. Disponible en: http://www.boe.es/diario_boe/txt. php?id=BOE-A-2012-14115

Real Decreto-ley 1/2015, de 27 de febrero, de mecanismo de segunda oportunidad, reducción de carga financiera y otras medidas de orden social. Boletín Oficial del Estado, de 28 de febrero de 2015, núm. 51, pp. 19058-19101. Disponible en: http://www.boe.es/diario_ boe/txt.php?id=BOE-A-2015-2109 